\title{
A REDE SOCIOASSISTENCIAL NO COMBATE À VIOLÊNCIA DOMÉSTICA CONTRA A MULHER NO BRASIL
}

\section{THE SOCIOASSISTENTIAL NETWORK IN COMBAT DOMESTIC VIOLENCE AGAINST WOMEN IN BRAZIL}

\author{
Soraia Goncalves Moura ${ }^{1}$ \\ Isabel de Freitas $\mathrm{Melo}^{2}$ \\ Suelânia Cristina Gonzaga de Figueiredo ${ }^{3}$
}

\section{RESUMO}

A violência doméstica contra a mulher é uma das expressões da questão social que afeta todas as sociedades. Este artigo faz um estudo acerca da Rede Socioassistencial no combate à violência doméstica contra a mulher no Brasil, enfatizando os serviços de atendimento que priorizam a proteção a essas mulheres. A finalidade desta rede, na qual o Assistente Social é um dos principais agentes articuladores, é a promoção, proteção e garantia dos direitos da mulher vítima de violência doméstica. Desta forma, este estudo, por meio de pesquisa bibliográfica, enfatiza as principais instituições que atuam de forma direta com a Rede Socioassistencial, proporcionando, assim, maior visibilidade, tanto da oferta dos serviços quanto da garantia dos direitos das mulheres vítimas da violência doméstica.

PALAVRAS-CHAVE: Violência doméstica. Mulher; Rede Socioassistencial; Articulador.

\begin{abstract}
Domestic violence against women is one of the expressions of the social questions that affects all societies. The present article makes a study about the Socio Assistance Network in the fight against domestic violence towards women in Brazil, emphasizing the services that prioritize the protection of these women. The aim of the Social Assistance Network that acts directly through the social assistant, is to promote, protect and guarantee the rights of women, victims of domestic violence. This bibliographical research emphasizes the main institutions that work with the Social Assistance Network, focusing on the provision of services and guaranteeing the rights of women, victims of domestic violence.
\end{abstract}

KEY WORDS: Domestic violence; Women; Social Assistance Network; Articulator.

\section{INTRODUÇÃO}

A violência doméstica contra a mulher é uma das expressões da questão social que afeta todas as camadas da sociedade, sendo reflexo de uma realidade histórica baseada na desigualdade da relação de poder entre os sexos, da subordinação e da inferioridade da mulher frente ao homem. Dessa forma, na atualidade se pode contar com os serviços de proteção e

\footnotetext{
${ }^{1}$ Bacharel em Serviço Social. Pós-graduação Lato Sensu Assistência Social e Família (FAMETRO). E-mail: soraiamoura15@gmail.com

${ }^{2}$ Bacharel em Serviço Social. Pós-graduação Lato Sensu Assistência Social e Família (FAMETRO). E-mail: isabelmfreitas26@gmaill.com

${ }^{3}$ Economista. Doutora em Ciência da Educação. Coordenadora de Pesquisa do Centro Universitário FametroCEUNIFAMETRO. E-mail: suefi@ hotmail.com
} 
atendimento social as mulheres vítimas de violência doméstica, promovendo meios para que ela fortaleça sua autoestima e autonomia. Para tanto, o sistema em Rede Socioassistencial visa à promoção da garantia dos direitos da mulher vítima de violência doméstica, sendo essa uma das demandas pertinentes em vários campos de atuação do Assistente Social.

O interesse acerca da temática emergiu com intuito de contribuir para dar mais visibilidade ao combate à violência doméstica contra a mulher e suas dimensões, bem como possibilitar o acesso à Rede Socioassistencial para a garantia de seus direitos.

O presente artigo tem por objetivo fazer um estudo acerca da Rede Socioassistencial no combate à violência doméstica contra a mulher no Brasil, enfatizando os serviços de atendimento que priorizam a proteção a essas mulheres. Pretende-se chamar a atenção para o fato de que essa problemática independe de cor, raça, religião, idade, cultura, classe social ou qualquer aspecto tangível ou inteligível do universo feminino. Tal violência atinge uma grande parcela da população feminina em relacionamentos afetivos, seja entre diferentes gêneros ou homoafetivos.

A Organização das Nações Unidas (ONU, 2006, p. 1) afirma que a violência contra a mulher "é uma grave violação aos direitos humanos, onde afeta negativamente o bem-estar geral das mulheres e sua família e as impede de participar plenamente da vida ativa na sociedade", prejudicando assim a sua integridade física, moral e psicológica face às relações intrafamiliares a qual está inserida.

Partindo desse pressuposto, a Rede Socioassistencial e seus aparatos legais são de suma importância no combate à violência doméstica contra a mulher no Brasil, sendo o Assistente Social um dos principais agentes articuladores que atuam no auxílio e no combate a esse paradigma, portanto a Rede Socioassistencial é primordial para que essas vítimas tenham as consequências da violência minimizadas e também para que outros casos sejam prevenidos e denunciados, com políticas públicas voltadas para essa demanda proporcionando a defesa dessas mulheres que sofrem violência doméstica.

\section{VIOLÊNCIA DOMÉSTICA CONTRA A MULHER NO BRASIL}

A violência doméstica contra a mulher não é uma situação recente e perpassa as classes sociais, sendo reflexo de uma realidade histórica baseada na desigualdade da relação de poder entre os sexos, da subordinação e da inferioridade da mulher frente ao homem, bem como nos relacionamentos homoafetivos onde mulheres lésbicas e bissexuais também estão 
propensas à violência doméstica, sendo esse um grave problema que carece ser reconhecido e enfrentado, tanto pela sociedade como pelos órgãos governamentais.

Violência Doméstica ou Intrafamiliar, de acordo com Costa (2006), "é aquela explícita ou velada, praticada dentro do lar, no âmbito familiar, entre indivíduos que possuam parentesco civil ou parentesco natural, ambos podendo existir na forma de linha reta, por afinidade ou por vontade expressa (como na adoção)". O autor destaca que a violência doméstica pode ocorrer contra diversos familiares, entre eles: crianças/adolescentes, mulher/homem e até mesmo idosos. Todas essas configurações podem tomar forma na violência doméstica, materializando-se em crimes e graves violações a direitos fundamentais inerentes à pessoa humana.

Para Minayo (2006), a violência não é um ato único, mas algo múltiplo. Segundo a autora, quem analisa os eventos violentos descobre que eles se referem a conflitos de autoridade, a lutas de poder e a vontade de domínio, de posse e de aniquilamento do outro ou de seus bens, e descreve a palavra "violência" que possui origem latina e vem da palavra vis, que quer dizer força e se refere às noções de constrangimento e de uso da superioridade física sobre o outro. Machado e Gonçalves (2003) consideram fatores contribuintes para a violência: "O isolamento (geográfico, físico, afetivo e social), o poder e o domínio ou a influência moral", e ainda consideram que as causas mais próximas que tendem para a violência doméstica estão baseadas: "Nas crenças e atitudes, situações de stress (desemprego; problemas financeiros; gravidez; mudanças de papel), frustração, alcoolismo, vivências infantis de agressão ou de violência parental, personalidade sádica, perturbações mentais ou físicas".

Segundo a Lei Maria da Penha (Lei 11.340/2006), existem diferentes formas de violência doméstica contra a mulher, explícito em seu art. $7^{\circ}$ : tais como: a violência física, entendida como qualquer conduta que ofenda sua integridade ou saúde corporal; a violência psicológica, entendida como qualquer conduta que lhe cause dano emocional e diminuição da autoestima ou que lhe prejudique e perturbe o pleno desenvolvimento ou que vise degradar ou controlar suas ações, comportamentos, crenças e decisões, mediante ameaça, constrangimento, humilhação, manipulação, isolamento, vigilância constante, perseguição contumaz, insulto, chantagem, ridicularização, exploração e limitação do direito de ir e vir ou qualquer outro meio que lhe cause prejuízo à saúde psicológica e à autodeterminação.

Em conformidade com o referido artigo da citada Lei, destaca-se também a violência sexual, entendida como qualquer conduta que a constranja a presenciar, a manter ou 
a participar de relação sexual não desejada, mediante intimidação, ameaça, coação ou uso da força; que a induza a comercializar ou a utilizar, de qualquer modo, a sua sexualidade, [...],contendo na Lei também a violência patrimonial, entendida como qualquer conduta que configure retenção, subtração, destruição parcial ou total de seus objetos, instrumentos de trabalho, documentos pessoais, bens, valores e direitos ou recursos econômicos e também a violência moral sendo aquela entendida como qualquer conduta que configure calúnia, difamação ou injúria. Todas essas e outras mencionadas são consideradas como tipos de violência doméstica cometidas contra a mulher.

Cada tipo de violência, segundo Kashani e Allan (1998), "gera prejuízos nas esferas do desenvolvimento físico, cognitivo, social, moral, emocional ou afetivo", sendo destacado pelos referidos autores que as manifestações físicas da violência podem ser “agudas, como as inflamações, contusões, hematomas, ou crônicas, deixando sequelas para toda a vida, como as limitações no movimento motor, traumatismos, a instalação de deficiências físicas, entre outras", destacando que os sintomas psicológicos frequentemente encontrados em vítimas de violência doméstica são: “insônia, pesadelos, falta de concentração, irritabilidade, falta de apetite, e até o aparecimento de sérios problemas mentais como a depressão, ansiedade, síndrome do pânico, estresse pós-traumático", ressaltando ainda, "os comportamentos autodestrutivos, como o uso de álcool e drogas, ou mesmo tentativas de suicídio".

Sendo assim, a violência doméstica desencadeia inúmeras consequências, seja simbólica ou por meio de uma ação com uso da força física, é realizada por outrem com a finalidade de submeter o indivíduo e a liberdade do outro para obter vantagens próprias, mesmo que isso cause danos irreversíveis à vítima, como é o caso da violência moral e psicológica, que fere a dignidade dessas mulheres. O impacto dessa realidade afeta desde a percepção da mulher sobre si mesma, algo que se reflete nos seus sentimentos de insegurança e impotência, até suas relações com o meio social.

A Lei Maria da Penha (Lei 11.340/2006) foi criada para coibir e punir o agressor que pratica atos de violência doméstica contra a mulher e tornou possível que agressores de mulheres no âmbito doméstico ou familiar sejam presos em flagrante ou tenham sua prisão preventiva decretada. Prevê, ainda, medidas que determinam a saída do agressor do domicílio e a proibição de que ele se aproxime da mulher agredida e dos (as) filhos (medida protetiva).

A referida Lei tem como objetivo garantir os direitos fundamentais a todas as mulheres, tendo como meta prevenir e eliminar todas as formas de violência doméstica contra 
a mulher, visando punir os agressores e principalmente dando assistência e proteção as mulheres em situação de violência doméstica. Isso é uma vitória para as mulheres nos dias atuais, pois depois de sofrerem ameaças, discriminações e violências em toda sua trajetória histórica, a mulher vem alcançando seus direitos e se consolidando na sociedade, como um ser presente e atuante em busca de uma vida mais digna a ser vivida.

Conforme a Lei Maria da Penha art. 20, "toda mulher, independentemente de classe, raça, etnia, orientação sexual, renda, cultura, nível educacional, idade e religião, goza dos direitos fundamentais inerentes à pessoa humana, sendo-lhe asseguradas as oportunidades e facilidades para viver sem violência [...]". A Lei Maria da Penha vem para somar as conquistas alcançadas pelas mulheres e faz com que esse grupo desperte para lutar por políticas que venham ao encontro de suas necessidades básicas, sendo estimuladas a participarem de movimentos que visem ao fim da violência e a conquista dos seus direitos.

A Secretaria Nacional de Políticas para as Mulheres criou em 2005, a Central de Atendimento à Mulher-Ligue 180, criada para orientar as mulheres em situação de violência sobre seus direitos e sobre os serviços especializados, bem como para auxiliar no monitoramento da Rede de atendimento às mulheres em todo o território nacional, representando, portanto, um importante avanço no tocante à divulgação dos serviços de atendimento no combate a violência doméstica e à garantia de acesso das mulheres à rede.

De acordo com a Secretaria Nacional de Políticas para as Mulheres (SPM), a partir de dados fornecidos pelo Ligue-180 no ano de 2015/2016, sendo feito um comparativo bianual desses dados, a referida secretaria destaca que, dos atendimentos realizados de janeiro a outubro de 2015, do total de atendimentos, 63.090 foram relatos de violência. Dos quais se pode destacar dentre os relatos, $49,82 \%$ corresponderam a de violência física; $30,40 \%$ de violência psicológica; 7,33\% de violência moral; $2,19 \%$ de violência patrimonial; 4,86\% de violência sexual. Do total de atendimentos no $01^{\circ}$ semestre de 2016, 67.962 corresponderam a relatos de violência. Dentre os relatos, $51,06 \%$ corresponderam à violência física; 31,10\%, violência psicológica; $6,51 \%$, violência moral; 4,30\%, violência sexual; $1,93 \%$, violência patrimonial. (BRASIL, 2016)

De acordo com a Secretaria Nacional de Políticas para as Mulheres (SPM), no $01^{\circ}$ semestre de 2016 , foi notado um aumento de $133 \%$ nos relatos relacionados à violência doméstica e familiar, comparando-se com o mesmo período de 2015. Além disso, do total de informações prestadas (299.743), 25\% (76.633) se referiram à Lei Maria da Penha e à violência doméstica e familiar, nota-se também com esses dados registrados pela mencionada 
Secretaria que, as próprias vítimas da violência doméstica estão denunciando seus agressores, ou seja, a Rede de combate à violência doméstica está mais atuante e proporcionando a essas mulheres mais autonomia e segurança para fazer as denúncias (BRASIL, 2016)

A Secretaria acima citada destaca que esses dados apontam para a percepção de que a violência doméstica está sendo cada vez mais denunciada em um patamar maior, pois o acesso e conhecimento à Lei Maria da Penha induzem mais pessoas a denunciar os casos de violência doméstica contra a mulher no Brasil, diminuindo assim notoriamente os casos de violência, devido à punição dos agressores de acordo com Lei.

A referida Secretaria aponta para a importância do avanço legislativo, que contribui para uma maior conscientização da sociedade sobre seus direitos referentes ao fenômeno da violência doméstica, proporcionando o aumento significativo no conhecimento de seus direitos na busca pelos serviços oferecidos pelo Ligue 180. Segundo a Política Nacional de Enfrentamento à Violência contra as Mulheres: "cabe à Central o encaminhamento da mulher para os serviços da rede de atendimento mais próxima, assim como prestar informações sobre os demais serviços disponíveis para o enfrentamento à violência" (SPM, 2007).

Segundo a Secretaria Nacional de Políticas para as Mulheres (SPM), a partir da Lei Maria da Penha, os crimes cometidos contra as mulheres devem ser julgados "nos juizados/varas especializadas de violência doméstica e familiar, competência civil e criminal equipados por uma equipe multidisciplinar composta por assistentes sociais e psicólogos treinados para um atendimento especializado e humanizado". É através do trabalho realizado por esses profissionais que o combate a violência doméstica se torna mais eficaz, graças a uma equipe capacitada para combater todos os tipos de violência contra a mulher.

O Assistente Social é, portanto, parte de uma equipe multidisciplinar que atua no combate à violência doméstica, inserido nas instituições que prestam atendimento à mulher vítima de violência. Conforme Lisboa e Pinheiro (2005), alguns dos instrumentos técnicooperativos utilizados na atuação do Assistente Social no atendimento às vítimas de violência doméstica são "entrevista, visita domiciliar, reuniões em grupo, documentação, relatórios, parecer social, planejamento de programas, projetos, construção de indicadores, pesquisa, relatórios, articulação em Rede”. Todos esses instrumentos possibilitam ao profissional agir e estabelecer estratégias de intervenção no combate à violência doméstica contra a mulher, atuando também em conjunto com a Rede Socioassistencial que ampara essa demanda. 


\section{REDE SOCIOASSISTENCIAL DE ATENDIMENTO ÀS MULHERES VÍTIMAS DE VIOLÊNCIA DOMÉSTICA}

A Política Nacional de Assistência Social, especificadamente a Norma Operacional Básica do Sistema Único de Assistência Social, preceitua que "a Rede Socioassistencial é um conjunto integrado de iniciativas públicas e da sociedade, que ofertam e operam benefícios, serviços, programas e projetos, o que supõe a articulação entre todas estas unidades de provisão de proteção social, sob a hierarquia de básica e especial e ainda por níveis de complexidade" (BRASIL, 2005).

Os serviços de proteção e atendimento social às mulheres vítimas de violência doméstica podem contar com a Rede Socioassistencial no aparato legal de seus direitos. Os atendimentos em Rede visam o término da situação de violência e a prevenção de futuro atos de agressão, promovendo meios para que ela fortaleça sua autoestima e autonomia. Para tanto, esse sistema visa a garantia dos direitos da mulher vítima de violência doméstica.

Podendo elencar como órgãos integrantes do sistema de proteção à mulher vítima de violência doméstica: as Delegacias especializadas da mulher, Distritos Integrados de Polícias (DIPs), Serviço de Apoio Emergencial a Mulher-SAPEM (Casa Abrigo), Centro de Referência Especializado de Assistência Social (CREAS), Núcleo de Atendimento da Mulher Vítima de Violência, Defensorias Públicas, Juizados Especializados no Combate a Violência Doméstica e Familiar contra a Mulher, Unidades de Saúde, Central de Atendimento à MulherLigue 180 da Secretaria de Políticas para as Mulheres e demais instituições que atuam no combate à violência doméstica.

Na Lei 11.340/2006, conhecida por tratar de casos de agressão física entre cônjuges, o texto também identifica como violência doméstica o sofrimento psicológico, como o isolamento da mulher, o constrangimento, a vigilância constante e o insulto, entre outros comportamentos agressivos e machistas.

A primeira articulação citada na referida Lei é a integralidade ocupacional do Poder Judiciário, do Ministério Público, da Defensoria Pública com as áreas de segurança pública, assistência social, saúde, educação, trabalho e habitação. Além dessa articulação de fundamental importância para o efetivo funcionamento dos serviços, a lei apresenta as diretrizes para as políticas públicas como a produção de estudos e pesquisas com perspectivas de gênero e a disseminação dos valores éticos de respeito à dignidade da pessoa humana com perspectivas de gênero, raça e etnia. 
Na proteção às mulheres, A Lei no 11.340/06, em seu artigo 23, preocupou-se com a proteção das vítimas, trazendo medidas protetivas de urgência, sendo destacado por Dias (2007), que as medidas de proteção às vítimas da violência doméstica e familiar "podem ser determinadas pelo juiz competente, ou ainda pela autoridade policial, sendo que o Ministério Público também tem esse dever, por se tratar de um serviço público de segurança, mesmo que seja na esfera administrativa".

De acordo com a Política Nacional de Enfrentamento à Violência contra as Mulheres, "a Rede socioassistencial se fundamenta na prevenção, combate e enfrentamento à violência contra as mulheres, assim como para a assistência e a proteção às mulheres em situação de violência". Dessa maneira, o Estado protege as mulheres vítimas de violência doméstica, tendo responsabilidade de dar suporte na reconstituição de suas vidas. Para isso, prevê a articulação entre as áreas de assistência social, saúde, educação, justiça, segurança pública, entre outras. Essa integração permite a inserção das vítimas no cadastro de programas socioassistenciais dos governos Federal, Estadual e Municipal, no sentido de garantir os direitos das mulheres a uma vida sem violência.

Nesse âmbito de atuação, o Serviço Social enquanto profissão ocupa um espaço na divisão social e técnica do trabalho, possuindo por meio de sua legitimidade respaldo para atuação na sociedade. Ao estabelecer relações próprias do seu processo de intervenção que são específicas ao seu campo de ação, ele se conecta e constrói vínculos na sociedade onde irá intervir, bem como uma atuação coerente e comprometida para a concretização do Projeto Ético-Político. Iamamoto (2007) destaca que na atualidade "Um dos maiores desafios que o Serviço Social vive no presente é desenvolver sua capacidade de decifrar a realidade e construir propostas de trabalho criativas [...], enfim, ser um profissional propositivo e não só executivo", utilizando-se de seus saberes e competências para o agir profissional.

Assim, o Assistente Social é solicitado para atuar em diversas áreas onde se apresenta as expressões da questão social, desenvolvendo sua prática no cotidiano institucional, sendo fundamental que todos esses serviços funcionem a partir de uma perspectiva intersetorial, atuando de forma articulada e integrada, logo essa gestão em Rede permitirá o melhor alcance da efetivação das políticas públicas mediante sua intervenção no combate à violência doméstica, concretizando o acesso aos seus direitos sociais.

Os diversos campos sócio-ocupacionais, integrantes da Rede Socioassistencial, são os principais meios de contato do Assistente Social com os usuários. A grande maioria dos profissionais de Serviço Social desenvolve sua atuação através das instituições. Desse 
modo, cabe ao profissional conhecer as especificidades das instituições pertencentes à Rede Socioassistencial, a fim de promover o acesso dos usuários aos seus direitos legalmente garantidos.

\section{O ASSISTENTE SOCIAL, AGENTE ARTICULADOR DO SISTEMA EM REDE SOCIOASSISTENCIAL}

$\mathrm{Na}$ trajetória histórica do Serviço Social, o profissional tem sido um dos agentes que mais atuam na relação direta com a população usuária, desde os primórdios da profissão, desvelando várias expressões da questão social que surgem a cada período na sociedade, onde implementam, e executam essa nova e desafiante política.

O Serviço Social, enquanto profissão, possui a Lei 8.662/93 de regulamentação, que expressa à legitimação e reconhecimento da profissão definindo as competências e atribuições privativas do profissional. Sendo assim, o Assistente Social não é um mero executor de tarefas, mas sim um profissional propositivo, interventivo e um cientista das causas sociais e na elaboração e execução de projetos étnicos, políticos, econômicos educacionais e sociais trabalhando dessa forma possibilitando a articulação em Rede em diferentes campos de atuação.

Iamamoto (2008) afirma que o trabalho do Assistente Social "adquire materialidade no conjunto das regulamentações profissionais", requerendo perspicácia para a inovação de sua práxis. Conforme Netto (2010), “os projetos profissionais apresentam a autoimagem da profissão que a legitimam socialmente [...] e formulam os requisitos (teóricos, práticos e institucionais) para seu exercício”, podendo intervir formulando e implementando propostas, por meio das políticas públicas, sociais, econômicas e culturais para o enfrentamento de tais expressões.

Partindo desse pressuposto, Iamamoto (2008) coloca que o perfil do profissional de Serviço Social demandado na atualidade, aponta três dimensões que devem ser do domínio do Assistente Social contemporâneo. "As dimensões ético-política, teórico-metodológica e técnico-operativa", vão direcionar o agir profissional a partir da identidade profissional construída pelo seu Projeto Ético-Político, atendendo assim às demandas que lhes forem apresentadas nos espaços sócio-ocupacionais de atuação.

O profissional de Serviço Social, portanto, depara-se com as múltiplas expressões da questão social em suas diversas áreas de atuação, dentre as quais atua no combate à violência doméstica contra a mulher, sendo articulador do sistema da Rede Socioassistencial, 
e promovendo e contribuindo para a melhoria da qualidade de vida dos sujeitos sociais, os quais se encontram em situação de vulnerabilidade social e risco pessoal, desta forma garantindo aos cidadãos o conhecimento dos direitos socioassistenciais em sua defesa.

\section{CONSIDERAÇÕES FINAIS}

Face ao que vimos nesse trabalho, a sociedade está mais consciente quanto aos agravantes da violência doméstica e o número de denúncias aumenta de forma significativa. As políticas públicas criadas para proteção a essas mulheres vêm dando ênfase ao Sistema em Rede Socioassistencial como forma de amparo legal na proteção às mulheres vítimas de violência doméstica e contribuído para efetivação de seus direitos enquanto cidadãs, dando assim mais segurança a essas vítimas.

Sendo assim, a Rede Socioassistencial é o principal meio de acesso aos serviços garantidos legalmente e viabilizados pelas políticas públicas, que proporcionam aos sujeitos socias maior defesa, proteção e garantia dos direitos da mulher vítima de violência doméstica. As instituições e os profissionais devem, portanto, estar cada vez mais informados e capacitados a respeito da complexidade da violência doméstica, com conhecimentos e atualizações da rede de combate a esse fenômeno. Dessa forma, podendo prevenir, combater e punir os agressores de acordo com a Lei.

Com isso, as vítimas podem sair desse ciclo de violência, que degrada a sua integridade. A Rede Socioassistencial é o caminho que auxilia no empoderamento a essas mulheres, dando-lhes suporte psicológico, social e acesso à justiça, e trazendo assim o resgate das mesmas como sujeitos de direitos, ao promover um meio para que elas fortaleçam sua autoestima e autonomia, no redirecionamento e estabelecimento de novos projetos de vida.

Pode-se concluir que, apesar de haver as legislações que atualmente amparem a mulher, ainda existe uma grande ausência de políticas públicas que beneficiem as mulheres vítimas de violência doméstica e, consequentemente, de mais programas e projetos que garantam à construção e reconstrução de sua autonomia onde essas possam ter mais defesa e proteção de seus direitos fundamentais e sociais.

\section{REFERÊNCIAS}

BRASIL. Política Nacional de Enfrentamento à Violência Contra as Mulheres. Disponível em: <http://www.spm.gov.br/central-de-conteudos/publicacoes> Acesso em 12 abr. 2018 
BRASIL. Rede de Enfrentamento à Violência contra as Mulheres. Disponível em: <http://www.spm.gov.br/central-de-conteudos/publicacoes> Acesso em 12 abr. 2018.

BALANÇO 180_2015/ 2016. Publicado em 2016. Disponível em: < http:// www.spm.gov.br/central-de-conteudos/publicacoes > Acesso em 12 abr. 2018.

Lei $n^{\circ}$ 11.340/2006. Lei Maria da Penha: a luta fazendo a lei. Brasília, 2006.

. Ministério do Desenvolvimento Social e Combate à Fome. Norma Operacional Básica NOB/SUAS. Brasília, 2005.

COSTA, Marli Marlene Moraes da. Violência doméstica: quando a vítima é criança ou adolescente: uma leitura interdisciplinar. Florianópolis: OAB - SC, 2006.

DIAS, Maria Berenice. A Lei Maria da Penha na Justiça: A efetividade da Lei 11.340/2006 de combate à violência doméstica e familiar contra a mulher. São Paulo: Revista dos Tribunais, 2007.

IAMAMOTO, Marilda Villela. Serviço na Contemporaneidade: Trabalho e Formação Profissional. 14 ed. São Paulo: Cortez, 2008.

KASHANI, Javad H.; ALLAN, Wesley D. The impact of family violence on children and adolescents. Thousand Oaks, Ca: Sage, 1998.

LISBOA, Tereza K; PINHEIRO, Eliane Aparecida. A intervenção do Serviço Social junto á questão da violência contra a mulher. Katálysis, Florianópolis, v.8, n.2 p. 199-210, jul./dez.2005.

MACHADO, C. \& GONÇALVES, R. A. Violência e Vítimas de Crimes. $2^{\mathrm{a}}$ ed. Vol.1. Coimbra: Quarteto, 2003.

MINAYO, M. C. S. Violência e Saúde. Rio de Janeiro: Editora Fiocruz, 2006.

NETTO, José Paulo. A Construção do Projeto Ético-Político do Serviço Social; Serviço Social e Saúde: Formação e Trabalho Profissional; Brasília; 2010.

ONU - ORGANIZAÇÃO DAS NAÇÕES UNIDAS. In-depth study on all forms of violence against women. New York, 2006. 